\title{
Statistic Analysis of Industrial Potential in the Russian Federation: A Regional Aspect
}

\author{
Olga V. Bakanach \\ Natalya V. Proskurina \\ Yury A. Tokarev \\ Nina I. Merkushova
}

Samara State University of Economics, Department of Statistics; Email: bakanach@mail.ru

\author{
Doi:10.5901/mjss.2015.v6n6s3p384
}

\section{Abstract}

\begin{abstract}
At present the priority direction of the economy of the Russian Federation in conditions of import substitution is the development of its own industrial production. In developed countries, it accounts for a third of GDP. However, at the present stage of industrial development there are some challenges, including: volatility, reduction of the most important indicators of the efficiency of production, the slow improvement in the structure of industrial production and exports, quite high physical and moral deterioration of fixed assets, high cost of resources, etc. Today the policy of industrial development is based on a number of programs, the main objective of which is the increasing of the share of competitive domestic products on the domestic and global markets through the development of existing and creation of new industries. In the new economic conditions, when the industrial complex of Russia and its regions have to overcome the consequences of the economic crisis, the problem of the search of additional possibilities to ensure the sustainability of industrial enterprises and the complex as a whole on the basis of the effective use of the potential and resource components, is very actual. The solution to this problem is based on a comprehensive study of the industrial potential, emerging at different levels of the federal socio-economic system, construction of potential management systems adequate to the new market conditions and macro-economic benchmarks, as well as industrial policy at the regional level. The goal of this study is statistical evaluation of the industrial potential of regions of the Russian Federation. Achieving this goal involves the following tasks: -to consider approaches to the concept "industrial potential of the region"; - to implement a multi-dimensional classification of regions in terms of industrial development using the methods of cluster analysis; -to identified statistically significant factors influencing the level of industrial development in the regions using multivariate analysis methods; - to build multifactor regression models that allow to set a quantitative expression of relationships and dependencies of basic indicators of industrial production in view of their stochastic nature.
\end{abstract}

Keywords: industrial potential, statistics, region, classification, method of canonical correlations, factor analysis, regression analysis.

\section{Introduction}

The development of any region is characterized by its economic potential, that is the total ability of the region's economy, its industries, businesses and farms to carry out production and business activities, to provide products, goods, services, meet the needs of the population, social needs, to ensure the development of production and consumption.

The economic potential of the region is primarily determined by production capacity, which, in its turn, is determined by the industrial capacity.

The concept of the industrial potential of the region is interpreted as a combined ability of enterprises in the region to create and produce competitive products, promote them on the market, make profit and provide the required level of service.

The industrial potential of the region carries out means of production as well as production of consumer goods.

Returning to the concept of the industrial potential of the region, it should be noted that the most important direction of development is the process of its updating, technological modernization, accelerated development of the most technologically advanced industries. In addition to the regional economy it is important to develop local industry which plays an important role in creating jobs, meeting the domestic demand, promotes the integrated development of the territory.

Currently, there is no single definition of "industry". Various sources (both scientific and encyclopedic) use many interpretations. For example, Efremova T. considers industry manufacturing industry, covering the processing of raw 
materials, the development of mineral resources, the creation of the means of production and consumer goods (Efremova, 2001). Industry is the sector of the economy engaged in the production of industrial goods and the provision of industrial services (Azriliyan, 2008). Pilipenko E. and Grinyuk K. reviewed understanding of the evolution of industry in our country. In their opinion in the Soviet planned economy non-market approach dominated according to which industry meant the aggregate branch (division) of the national economy opposite to its other branches (divisions) - agriculture, transport, trade and so on. N. Modern market approach is characterized by an eclectic mix of diverse and even antagonistic concepts for obscure purposes (or rather, in the absence of clear objectives) which actually is a consequence of the mechanical application of the old, non-market concepts in market conditions (Grinyuk \& Pilipenko, 2013).

Such variety of definitions is largely due to the development of the economy and the beginning of transition from the All-Union Classification of Branches of National Economy to the National Classification of Economic Activities in 2002. However, current rules classifying sectors (sub-sectors) of the economy of the Russian Federation according to professional risk use the names of sectors (sub-sectors) of the economy in accordance with the All-Union Classification of Branches of National Economy.

As a result of transition from the All-Union Classification of Branches of National Economy to the National Classification of Economic Activities the borders of the existing activities changed. All industrial activities, for example, are divided into three sectors: C - "Mining", D - "Processing", E - "Production and distribution of electric energy, gas and water."

According to the spheres of use industry is divided into production of production means - group A (production of machines, tools, equipment, etc.) and production of commodities - group B (production of food, clothes, household appliances, housing, etc.)

The concept of the industrial potential was studied in the works of many researchers. For example, Svintsova A. (Svintsova 2001) considers it in the context of the factors of production; Zadumkin K. and Kondakov I. (Zadumkin \& Kondakov, 2010) relate it to scientific and technical progress, giving priority to the technical side of the issue; Buyuklyan A. (Buyuklyan, 2006) defines it as the basis of the ability to produce wealth in the industrial and transport sectors; Marshova N. (Marshova 2011) examines the industrial potential within the frame of the program of modernization of the Russian economy; Baranov I. considers it to be a factor of productivity growth - the most important condition for raising the living standards of the population of the country (Baranov, 2010). The most comprehensive definition is given by Smirnova T. who understands industrial potential of the territory as the totality of its production, financial, human resources, infrastructure capabilities that determine their readiness for the introduction of the latest scientific and technical achievements and technologies, the implementation of progressive structural shifts and institutional reforms aimed at improving efficiency of the economy and ensuring the development of the territory of the region's industry (Smirnova, 2012).

The questions of the development of industry and industrial potential were studied by the following researchers: Mishurov S.S. (Mishurov, 2005), Zhukov V.N. (Zhukov, 1955), Anchishkin A.I. (Anchishkin 1972), Abalkin L.I. (Abalkin, 1981), Chernikov D.A. (Chernikov, 1981), Shevchenko D.K. (Shevchenko, 1984), Figurnov E.B. (Figurnov, 1982), Misko K.M. (Misko, 1991), Hamilton F. (Hamilton, 1983) and others.

Such scientists as Granberg A.G. (Granberg 1973, 1988), Vedishchev A.I. (Vedishchev 1963), Kurakov L.P. (Kurakov, 1978), Strumilin S.G. (Strumilin, 1954) also contributed to solving of the problems of the development of the regional economic systems.

\section{Method}

Theoretical and methodological basis of the work consists of the works of the domestic and foreign scientists, the provisions of the theory of the market economy, the theory of statistics and economic statistics, applied statistics and econometric modeling, the methodological guides of the Federal State Statistics Service of the RF, materials of scientific seminars and conferences. Statistics tools of the research were general scientific and statistical methods: group method, method of cluster analysis, variance analysis, canonical correlation analysis, multivariate factor analysis, and correlation and regression analysis.

In order to determine the typology of regions in terms of industrial development of regions on the basis of consideration of the system of indicators cluster analysis with the use of the statistical package of data «STATISTICA» was performed.

Cluster analysis is a set of methods of multidimensional classification, the purpose of which is the formation of groups (clusters) of similar objects. 
Cluster analysis methods allow to solve the following problems:

1) classification of objects on the basis of features reflecting their essence and nature; this usually leads to a better knowledge of the totality of classified objects;

2) checking of suppositions about the existence of a structure in the studied set of objects, i.e. searching for the existing structure;

3) construction of new classifications for poorly studied phenomena when you need to establish relationships within the set and try to bring a structure in it.

Cluster analysis uses multi-dimensional approach to the formation of groups. As a rule clear borders of each group are not indicated and it is not known in advance how many groups it is appropriate to mark out in the researched set.

In this research, the use of cluster analysis made it possible to solve the following problems:

1) classification of the subjects of the Russian Federation with the account of features that reflect the level of development of industrial potential;

2) checking of suppositions about the existence of a structure in the studied set of subjects of the Russian Federation;

3) construction of a new classification of subjects of the Russian Federation according to the level of development of the industrial potential.

Normalized (standardized) values of the factors were analyzed by cluster analysis carried out with the use of hierarchical classification by Ward (to determine the optimal number of clusters in the set) and by method of $\mathrm{k}$ - average (to perform a comprehensive analysis of the results).

To identify the dependence of the main productive indicators from the group of factor variables correlation analysis is used in statistics. Here are the following types of it:

1) pair correlation - identifies the relationship between a productive indicator $Y$ and factor $X$;

2) multiple correlation analysis - sets and measures the degree of relationship between several variables $X$ and one variable $\mathrm{Y}$;

3) canonical correlation -studies the relationship in the case where there are many productive indicators $Y$ and several factors $X$.

To reach the goals of this work it is appropriate to use canonical correlation analysis. This method allows the simultaneous analysis of multiple correlations of output indicators and a large number of determinants.

The main purpose of the method of canonical correlations in the economic analysis is primarily in search of maximum correlation between the groups of studied variables. Also, its use makes it possible to reduce the amount of data by dropouts of insignificant factors. To accomplish the goals of this work is appropriate to canonical correlation analysis. This method allows the simultaneous analysis of multiple correlation output indicators and a large number of determinants.

The main purpose of the method of canonical correlations in the economic analysis is primarily in search of maximum correlation between the groups studied variables. Also, its use makes it possible to reduce the amount of raw data by dropouts of insignificant factors. With this method new arguments are determined - canonical values calculated as linear combinations of the original values. The new canonical values are selected so that the new coordinates directly indicate the values of correlation. In each group the linear combinations of the original variables are found having maximum correlation, and they are the first coordinates of the new systems. After that in each group the linear combinations having larger correlation than between any other linear combinations are studied. Construction continues as long as two new coordinate system are obtained.

Canonical correlations are always non-negative, and their main properties are the same as the ordinary - multiple correlation coefficients. The larger canonical correlations are, the more the groups of indicators $Y$ and $X$ are connected. The purpose of the method of canonical correlation is the study of the relationship between "conditions" and "results" of industrial production. At the same time indicators of "results" are independent variables and indicators of "conditions" are dependent ones.

The method of principal components is a private case of factor analysis. This method allows to achieve the following objectives:

1) restriction of feature space;

2) description of a set of objects of observation by not directly measurable, but objectively existing integral characteristics - the main components;

3) identification of the relationship of observed features with the newly obtained generalizing indicators.

The original data matrix $X$ for the implementation of the algorithm of component analysis is a rectangular table with the dimension $n \times k$, where $\mathrm{n}$ is the number of objects of observation (in this case - the number of regions of the Russian 
Federation) and $\mathrm{k}$ is the number of original features that characterize a set of objects of observation.

\section{Treatment}

To analyze and summarize the level of the industrial potential of regions of the Russian Federation according to the initial data provided by the Federal State Statistics Service, the system of statistical indicators is formed. It includes effective $(Y)$ and factorial features $(X)$ :

- $\quad$ the volume of self-produced goods, works and services, mln. rubles. (Y1);

- $\quad$ the turnover of industrial organizations per person employed in industrial production, mIn. rubles. (Y2);

- $\quad$ the share of GVA of industrial organizations in the structure of GVA of the region (Y3);

- investments in fixed assets of industrial enterprises per capita, thousands of rubles. (X1);

- $\quad$ the share of employed in industrial sphere in total employment,\% (X2);

- $\quad$ the profitability of processing organizations, $\%(X 3)$;

- $\quad$ the profitability of organizations engaged in mining, $\%(X 4)$;

- the profitability of companies engaged in the production and distribution of electric energy, gas and water, $\%$ (X5);

- $\quad$ the share of unprofitable enterprises engaged in mining, $\%(X 6)$;

- $\quad$ the share of unprofitable organizations engaged in processing, $\%(X 7)$

- the price index of producers of industrial products, $\%$ (X9);

- $\quad$ the proportion of the workers of industrial organizations engaged in heavy work, $\%$ (X10);

- the proportion of the workers of industrial organizations engaged in work with the intensity of the labor process, \% (X11);

- the proportion of the workers of industrial organizations working in conditions that do not meet hygienic standards of working conditions, $\%$ (X12);

- the return on assets of industrial enterprises, rubles (X13);

- Industrial Production Index,\% (X14);

- the proportion of the number of enterprises and organizations of industrial production in the total number of enterprises in Russia,\% (X15);

- $\quad$ power plants capacity, mln. KW, (X16);

- $\quad$ production of electricity per capita, thousands of KW - hours (X17);

- $\quad$ the average nominal monthly wage of 1 employee enterprises in mining, rub. (X18);

- the average nominal monthly wage of 1 employee of processing enterprises, rubles. (X19);

- $\quad$ the average nominal monthly wage of 1 employee of enterprises producing and distributing electricity, gas and water, rubles (X20). region.

Factor indicators can be divided into 4 blocks, characterizing various aspects of the industrial potential of the

The first block - "General economic indicators of the activities of industrial enterprises» (X9, X14, X15); the second block - "Material and technical base and investments of industrial enterprises» (X1, X13, X16, X17); the third block "Work in industrial production» (X10, X11, X12, X18, X19, X20) and the fourth block - "Finance of industrial enterprises» $(\mathrm{X} 3, \mathrm{X} 4, \mathrm{X} 5 \mathrm{X10}, \mathrm{X6}, \mathrm{X} 7, \mathrm{X} 8)$.

The system of indicators characterizing the industrial potential of the region can be presented as a scheme (Fig. 1). 


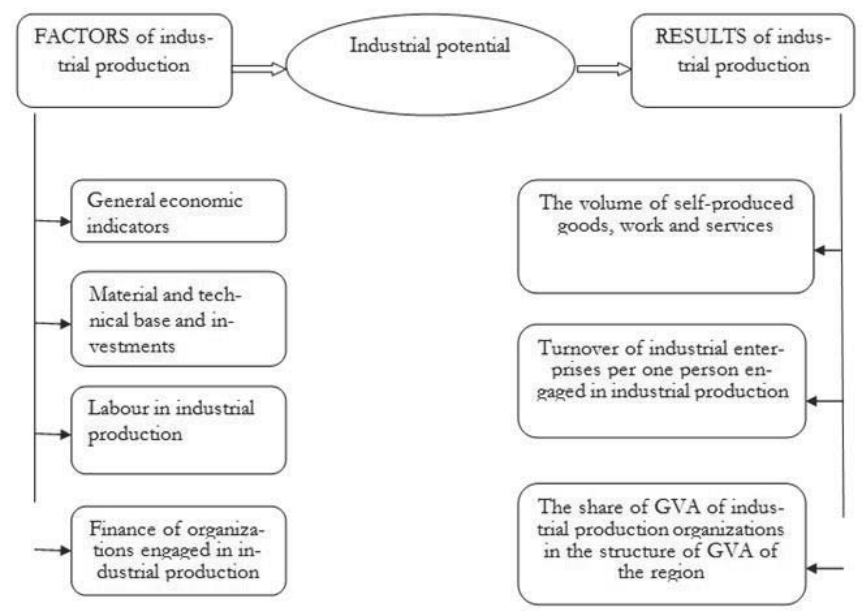

Figure 1. The scheme of effective and factor indicators of estimation of the industrial potential of the region

\section{Assessments}

As a result of cluster analysis three clusters of regions with the following characteristics were identified:

- $\quad$-the first cluster-high level of industrial potential;

- the third cluster- medium level of industrial potential;

- $\quad$-the second cluster-low level of industrial potential;

The clusters are presented in Table1.

Table 1. Clustering of regions according to the level of development of industrial potential

\begin{tabular}{|c|l|c|c|}
\hline № of cluster & The composition of cluster & $\begin{array}{c}\text { The number } \\
\text { of regions }\end{array}$ & Characteristics \\
\hline 1 & $\begin{array}{l}\text { Moscow, the Komi Republic, the Arkhangelsk Region, the Murmansk Region, the Tyumen Region, the } \\
\text { Krasnoyarsk Region, the Tomsk Region, the Republic of Sakha (Yakutia), the Kamchatka Region, the Amur } \\
\text { Region, the Magadan Region, the Sakhalin Region, the Chukotka Autonomous Region }\end{array}$ & 13 & high level \\
\hline 3 & $\begin{array}{l}\text { The Belgorod Region, the Vladimir Region, the Kaluga Region, the Kostroma Region, the Kursk Region, the } \\
\text { Lipetsk Region, the Moscow Region, the Smolensk Region, the Tver Region, the Tula Region, the Republic } \\
\text { of Karelia, the Vologda Region, the Kaliningrad Region, the Leningrad Region, St. Petersburg, the } \\
\text { Astrakhan Region, the Volgograd Region, the Republic of Bashkortostan, Tatarstan, Udmurtia, Perm, the } \\
\text { Kirov Region, the Nizhny Novgorod Region, the Orenburg Region, the Samara Region, the Saratov Region, } \\
\text { the Ulyanovsk Region, the Sverdlovsk Region, the Chelyabinsk Region, the Republic of Khakassia, the } \\
\text { Irkutsk Region, the Kemerovo Region, the Omsk Region, the Primorsk Region, the Khabarovsk Region }\end{array}$ & 34 & medium level \\
\hline 2 & $\begin{array}{l}\text { The Bryansk Region, the Voronezh Region, the Ivanovo Region, the Orel Region, the Ryazan Region, the } \\
\text { Tambov Region, the Yaroslavl Region, the Novgorod Region, the Pskov Region, the Republic of Adygea, } \\
\text { the Republic of Dagestan, the Republic of Ingushetia, the Kabardino-Balkar Republic, the Republic of } \\
\text { Kalmykia, the Karachay-Cherkess Republic, the Republic of North Ossetia-Alania, the Chechen Republic, } \\
\text { the Krasnodar Region, the Stavropolsky Region, the Rostov Region, the Republic of Mari-El, Mordovia, the } \\
\text { Chuvashia Republic, the Penza Region, the Ulyanovsk Region, the Kurgan Region, the Altai Republic, the } \\
\text { Republic of Buryatia, the Republic of Tuva, the Altai Region, Trans-Baikal Territory, the Novosibirsk Region, } \\
\text { the Jewish Autonomous Region }\end{array}$ & 33 & low level \\
& Total: & 80 & \\
\hline
\end{tabular}

The cluster with a high level of industrial capacity includes 13 regions, among which the leaders are the Chukotka Autonomous Region, the Tyumen Region and Moscow. These regions are characterized by high values of all the indicators, the largest of which are: investments in fixed assets of industrial enterprises per capita (X1), the return on assets of organizations engaged in the extraction of minerals (X4), the index of industrial production (X14), the average nominal monthly salary of the employee of enterprises engaged in mining, processing and distributing of electricity, gas and water (X18, X19, X20,). 
The cluster with low industrial capacity includes 33 regions. The regions of this cluster are characterized by the lowest values for all parameters, in particular - the return on assets of enterprises in industrial production (X13). The most lagging are the Novosibirsk Region, the Tambov Region and the Pskov Region.

It may be noted that the regions with high levels of industrial capacity are concentrated in the Urals, Siberian and Far Eastern Federal Districts. Regions with an average level are located mainly in the Volga, Central and North-Western Federal Districts. The Southern and Northern Caucasian Federal Districts are characterized by a low level. However, there are exceptions: the regions with the high value of the indicator - the city of St. Petersburg and the Murmansk Region within the North-West Federal District; regions with the low level of the indicator - the Primorsk and Khabarovsk Regions, the Jewish Autonomous Region as a part of the Far Eastern Federal District. This situation is explained by the peculiarities of the sectoral specialization of regions under consideration. Many regions have traditionally been the leading industrial centers of the Russian Federation, possessing of high resource and natural resources potential. Let us consider the features of the economic development of these regions.

On the territory of the Chukotka Autonomous Region coal for its own needs is mined, there are small fish processing companies and enterprises producing construction materials. A significant source of electricity in the region is Bilibinskaya NPP.

In the Tyumen Region there are the main oil and gas reserves of the country (64\%). There are also large deposits of oil - Samotlorskoye, Priobskoye, Kholmogorskoye, Krasnoleninskoye, Fyodorovskoye and large deposits of gas Urengoyskoye, Medvezhye, Yamburgskoye. Peat, quartz sand, limestone is mined there. About 400 deposits of raw materials for the production of construction materials are explored, ore minerals and gems are discovered (in particular, deposits of lead, copper, chromites). The main branch of specialization is the fuel industry, which accounts for $86.4 \%$ of the volume of industrial production. On the territory of the region there are a lot of plants processing hydrocarbon raw materials; the Russia's largest petrochemical company, which includes several powerful enterprises of oil and gas processing is also located there.

Moscow is the largest industrial and manufacturing center of Russia based on a qualified labour, a major center of mechanical engineering, including power engineering, machine tools, shipbuilding, instrumentation; ferrous and nonferrous metallurgy (production of aluminum alloys, non-ferrous metal and casting), chemical, light industry, printing industry. A significant number of enterprises of defense industry, oil, tire, metallurgy and many other enterprises work on the territory of Moscow; there is a strong scientific and technology base for the production of electronic and optoelectronic devices, aviation and aerospace equipment, high-precision mechanical devices in it. We consider it necessary to note that in recent years there is a process of transferring production facilities outside of Moscow.

Thus, the leading regions that make up the first cluster with a high level of the Industrial capacity have significant reserves of natural resources, and are specialized in industrial production.

The constructed typology of regions can be used for the development of a regional policy and for diagnostics of socio-economic situation in regions, for example, for business purposes.

Evidence-based regional policy must take into account the types of regions allocated on the basis of their characteristics: natural, economic, social and others. This will make it possible to take concrete steps to eliminate disproportions of territorial development.

It is necessary to establish which factors lead to the differentiation of regions in terms of industrial production. That means it is necessary to detect the presence of statistical relationship between these effective and factorial signs. Realization of this goal is carried out by the method of canonical correlations.

To implement the method of canonical correlations, from the totality of previously considered indicators there were picked out the factors of "conditions" of production (Block1-X9, X14, X15; Block $2-\mathrm{X} 1, \mathrm{X} 13$, X16, X17; Block 3-X2, X10, $\mathrm{X} 11, \mathrm{X} 12, \mathrm{X} 18, \mathrm{X} 19, \mathrm{X} 20 \mathrm{X17}$; Block4 -X3, X4, X5, X6, X7, X8) and indicators of "results" of industrial production (Y1, Y2 „, Y3) (the names of indicators are shown in Fig. 1).

The application of the method of canonical correlation between productive and factor indicators of industrial capacity revealed the highest correlation between groups of variables that made it possible, by dropping out insignificant variables, to reduce their number from 20 to 11 for making component method and correlation-regression analysis.

While implementing the method of principal components for the accurate reproduction of the correlation between variables and the variance it is necessary to find all the components, a large proportion of the variance of which is explained by a small number of principal components. The first component consists of heterogeneous indicators. They can be divided into two groups: "investment potential" - investments in the fixed capital of industrial enterprises per capita (X1) and indicators characterizing the average monthly wages (X18, X19, X20).

The second component corresponds to the essential load on the following indicators: the share of manufacturing employment in total employment (X2) and capital productivity of enterprises in industrial production (X13). 
The third main component after varimax rotation consists of the variables $\mathrm{X} 10, \mathrm{X} 11$, characterizing the proportion of the number of employees working at the enterprises with poor working conditions.

Thus, in the process of component analysis the following problems were solved:

1) the problems of data compression, that is the extraction of the most substantial part from the initial information due to the transition from the system input variables to the system of generalized factors;

2) the researched phenomenon (that is, the level of development of industrial enterprises) was characterized by much fewer generalized factors (principal components) in comparison with the number of initial features.

On the basis of three selected principal components regression equations are constructed for the purpose of quantitative expression of productive indicators relationship (Y1, Y2, Y3) and the factors influencing them (Table 2).

The regression equation on the main component sis constructed according to the algorithm, where as arguments the main components are used, not the initial indicators. Since the principal components are uncorrelated, the problem of multicollinearity of factor variables does not occur.

Table 2. Results of regression models construction

\begin{tabular}{|l|c|c|c|c|c|}
\hline \multirow{2}{*}{ Regression equation } & \multicolumn{2}{|c|}{ Fisher criterion } & \multirow{2}{*}{ Approximation error, \% } & Correlation coefficient, \% & Determination coefficient, \% \\
\cline { 2 - 5 } & $\mathrm{F}_{\mathrm{p}}$ & $\mathrm{F}_{\mathrm{T}}$ & & 68 & 46 \\
\hline $\mathrm{Y}_{1}=0,756 \mathrm{~F}_{1}+0,99 \mathrm{~F}_{2}-0,233 \mathrm{~F}_{3}$ & 4,396 & 0,314 & 9,7 & 86 & 73 \\
\hline $\mathrm{Y}_{2}=0,889 \mathrm{~F}_{1}+0,242 \mathrm{~F}_{2}-0,053 \mathrm{~F}_{3}$ & 2,689 & 0,192 & 6,7 & 89 & 79 \\
\hline $\mathrm{Y}_{3}=0,324 \mathrm{~F}_{1}+0,813 \mathrm{~F}_{2}+0,227 \mathrm{~F}_{3}$ & 1,900 & 0,136 & 4,9 & 89 & \\
\hline
\end{tabular}

The parameters all three regression equations are recognized statistically significant as to the t-criterion of Student with $95 \%$ confidence.

Evaluation of the adequacy and reliability of statistical regression equations was tested with the use of classical statistical criteria - the coefficient of multiple determinations (R2) and the Fisher test (F). The constructed regression equations provide respectively $46 \%, 73 \%$ and $79 \%$ of the variation corresponding to the effective variable. Verification by the Fisher test confirmed the reliability of the regression equations (with a significance level of $5 \%$ ). The value of the average error of approximation does not exceed $10 \%$, which is a testament to the reliability and adequacy of the obtained regression equations.

Let us have a look at the first and the second equations. The first two principal components are in the direct dependence, and the third - in the negative dependence on the productive features. That is the decrease in the proportion of workers employed at the enterprises with poor working conditions should lead to the increase of the volume of goods shipped and the capital productivity of the industrial enterprises. The greatest load is imposed on the first principal component, which characterizes the investment potential and the average monthly wage.

For the first model, the correlation coefficient is $68 \%$, that is, it can be said that a productive indicator is closely related to the factors included in the equation. The coefficient of determination shows that the variation in the volume of of own production -made shipped goods, works and services is $46 \%$ explained by the variation of factor variables.

For the second model, the correlation coefficient is $86 \%$, the coefficient of determination is $73 \%$.

However, in the third model all three main components are in direct dependence on the productive indicator (the share of GVA of the industrial enterprises in the structure of GVA of the region). The greatest load is imposed on the second component characterizing the share of manufacturing employment in total employment and the capital productivity of industrial enterprises. The coefficient of correlation between the productive indicators and factor indicators is $89 \%$ means their close relationship. We can also note that the variation of the share of GVA of the industrial enterprises in the structure of GVA of the region is $79 \%$ that is explained by the variation of factor indicators - the main components.

Thus, with the use of regression analysis the adequate models which make it possible to identify the main parameters influencing the volume of industrial production and determining the potential of the regions were constructed.

\section{Results}

The practical significance of the results of the research is that the materials contained in it, formulated conclusions and recommendations can be used to monitor the formation and development of the industrial potential of the regions within the frame of individual researches of the territorial bodies of the Federal State Statistics Service and the relevant departments of the administrations of the subject of the Russian Federation. 


\section{References}

Baranov I.V. (2010) The Formation of the System of Management of the Production Potential of an Industrial Enterprise on the Basis of the Use of Effective Methodical Tools (Unpublished doctoral thesis). Orel State Technical University, Orel, Russia.

Buyuklyan A. A. (2006, № 5) The Economic Potential of a Recreation Zone. Success of the Modern natural History. p. 34-35.

Grinyuk K.P., Pilipenko E.V. (2013, № 3) Industry and Industrial Complex in Economic Science: the Problems of Theory. Business. Education. Law. , p. 126-130.

Efremova T.V. (2000) New Dictionary of the Russian Language. M.:Russian Language. 1233 p.

Zadumkin K.A., Kondakov I.A. (2010) Scientific and Technical Potential of the Region: Estimation of State and Development Perspectives., Vologda: ISERT RAN., 205 p.

Marshova N.T. (2011, № 7) Evaluation of the Structure of the Russian Industrial Potential and its Correspondence to the Tasks of Modernization of the Economy. Questions of Statistics., p. 30-43.

Svintsova A.P. (2001). Industrial Potential: Concept, Criteria, Structure. Collection of papers UGNTU, p. 103-106.

Smirnova T.G. (2012, № 12) Evaluation of the Industrial Potential of the Region (on the example of the Vologda Region). Modern Scientific Research and Innovations http://web.snauka.ru/issues/2012/12/19140

Hamilton F.I., Linge G.J.R. (1983, Vol. 3) Spatial Analysis, Industry and the Industrial Environment. Chichester, 1983. 